\title{
Erratum
}

Pieter Joosse, Carel Goslings, Jan van der Meulen, Kees-Jan Ponsen

\section{Blunt Traumatic Rupture of the Left Atrial Appendage}

Eur J Trauma Emerg Surg 2002;28:110-3

DOI 10.1007/s00068-002-1191-2

There was an error in the author's list: Please note the correct author name Johan Carel Goslings:

Pieter Joosse, Johan Carel Goslings, Jan van der Meulen, Kees-Jan Ponsen

Eur J Trauma Emerg Surg 2007;33:672

DOI 10.1007/s00068-007-9191-x 